\title{
Capsule Commentary on Borrero et al., Unintended Pregnancy and Contraceptive Use among Women Veterans: The ECUUN Study
}

\author{
Jeffrey L. Jackson, MD, MPH \\ Zablocki VAMC, Milwaukee, WI, USA.

$\mathrm{W}$ hile the Veterans Affairs (VA) population is predominantly men, women comprise the fastest-growing population of veterans. ${ }^{1}$ Borrero and colleagues ${ }^{2}$ surveyed a national sample of $2302 \mathrm{VA}$ women between 18 and 44 years of age and found that their rates of contraception use and unintended pregnancy were comparable to those seen in the US age-adjusted population, while use of long-acting contraception was significantly higher in the VA.

What is remarkable is that these results are being achieved in a population in which one would expect significantly worse outcomes. The VA population in general is more diverse, has greater poverty, and has a greater disease and mental health burden than the age-matched US population. ${ }^{3}$ This is a population that would be expected to have greater healthcare disparities and poorer outcomes. At present, US healthcare access and reproductive care options are under siege. The House Republicans' plan will reduce access to healthcare for our most vulnerable, and are actively working to reduce resources that support access to contraception. Hopefully reason will prevail in the US Senate. While prevailing political rhetoric is to rail about the quality of care provided by the VA, objective measures have consistently demonstrated that the VA achieves outcomes comparable to or better than those attained in non-VA settings. ${ }^{4}$ The implications for the potential health equity and reduction in care disparities from a single-payer system are obvious.

In both the veteran and general population, there is significant room for improvement. Nearly a third of pregnancies in

both populations are unintended, reflecting the fact that $30 \%$ of women at risk for pregnancy are using suboptimal contraceptive approaches. Before one can intelligently devise an intervention, a clearer elucidation of the current barriers is needed. The authors plan to investigate patient, provider and facility-level factors with their data, but this is unlikely to be sufficiently granular and is limited to only the VA. The VA is an ideal laboratory in which to test health interventions, since it is geographically diverse, has a universal electronic health record, centralized policy decisions, a universal health benefit and low costs for beneficiaries, though translating outcome improvement to non-VA settings can sometimes be difficult.

Corresponding Author: Jeffrey L. Jackson, MD, MPH; Zablocki VAMC, Milwaukee, WI, USA (e-mail: jjackson@mcw.edu).

\section{Compliance with Ethical Standards:}

Conflict of Interest: The author's only potential conflict of interest is that he is a VA primary care provider, though his panel includes no women of reproductive age.

\section{REFERENCES}

1. Frayne SM, Phibbs CS, Saechao F, et al. Sourcebook: Women Veterans in the Veterans Health Administration. Volume 3. Sociodemographics, Utilization, Costs of Care, and Health Profile. Washington DC: Department of Veterans Affairs;2014.

2. Borrero S, Callegari LS, Zhao X, Mor MK, Sileanu FE, Switzer G, Zickmund S, Washington DL, Zephyrin LC, Schwarz EB. Unintended pregnancy and contraceptive use among women Veterans: the ECUUN study. J Gen Intern Med doi:10.1007/s11606-017-4049-3

3. Agha Z, Lofgren R, VanRuiswyk J, Layde P. Are patients at Veterans Affairs medical centers sicker? A comparative analysis of health status and medical resource use. Arch Intern Med 2000;160:3252-3257.

4. O'Hanlon CE, Huang CY, Sloss EM, Price RA, Hussey P, Farmer CM, Gidengil CA. Comparing VA and non-VA Quality of Care: A Systematic Review. J Gen Intern Med 2017. 32(1):105-121. 